\section{Is infant empathy linked with later} externalizing problems?

\author{
By Dr. Jessica Edwards
}

Until recently, it has been assumed that young infants cannot feel empathy for others. ${ }^{1}$ However, emerging data suggest that this might not actually be the case. ${ }^{2}$ Now, Yael Paz and colleagues have examined empathy development during the first years of life, analysing data from 165 infants involved in a longitudinal, prospective study. They specifically studied whether early empathy (age 3-36 months) has a protective or predictive role for externalizing problems that emerge in early childhood (age 18-36 months).

The researchers found that higher empathy was a protective factor against subsequent externalizing problems at 36 months old for boys, and against increases in externalizing problems from 18 to 36 months for both sexes. In contrast, for girls higher empathy at 12 and 18 months old predicted greater externalizing problems at 18 months old. This link might shed new light on the meaning of early externalizing behaviours.

"The fact that these behaviours are tied to greater empathy in girls suggests that they might actually reflect an interest in others and attempts to communicate and interact with others (even if in unskilled or unregulated ways), rather than attempts to hurt others", says Paz. "Understanding the benign/positive intentions behind these behaviours might help the environment react in a more suitable way (e.g., to teach how to approach others, rather than to reprimand the child for being aggressive). It is quite possible that angry and harsh reactions to a toddlers' externalizing behaviours might actually imbue these behaviours with a negative meaning, and thus set off a negative cascade."

Overall, the researchers propose that experiences that promote empathy in young infants might have positive implications for childhood behaviour. "These findings have potential clinical implications, as they point to the utility of incorporating very early empathy-based interventions and prevention programs for at-risk groups", proposes Paz. "Given the early ages of the infants, such programs might focus on psycho-education regarding the importance of socio-emotional development during the first year of life."

\section{Referring to:}

Paz, Y., Orlitsky, T., Roth-Hanania, R., ZahnWaxler, C. \& Davidov, M. (2020), Predicting externalizing behavior in toddlerhood from early individual differences in empathy. J. Child Psychol. Psychiatr. doi: 10.1111/jcpp.13247.

\section{References:}

${ }^{1}$ Hoffman, M.L. (2001). Empathy and moral development: Implications for caring and justice. Cambridge, MA: Cambridge University Press.

2 Davidov, M., Paz, Y., Roth-Hanania, R., Uzefovsky F., Orlitsky, T., Mankuta, D. \& ZahnWaxler, C. (in press). Caring babies: Concern for others in distress during infancy. Developmental Science. https://doi.org/10.1111/desc.13016.

\section{Glossary:}

Empathy: Concern for others in distress, and cognitive awareness and exploration of that distress. In this study, empathy was assessed using behavioural observations while the children witnessed distress, including their mother pretending to be hurt and in pain. The researchers coded both empathic concern (reflected in facial expressions, vocalisations and gestures) and inquiry behaviour (such as intense looking, exploring gestures and verbal inquisitiveness).

Externalizing problems: maladaptive behaviours which are directed externally towards the environment. Examples include impulsivity, and antisocial or aggressive behaviours. Adult manifestations of externalizing problems can also include alcohol or substance misuse. 